\title{
CORRELAÇÃO DE ACHADOS MICROBIOLÓGICOS E CITOLÓGICOS COLETADOS POR BRONCOSCOPIA DE CÃES COM COLAPSO TRAQUEAL
}

\author{
(Correlation between microbiologic and cytological findings collected by \\ bronchoscopy in dogs with tracheal collapse)
}

\begin{abstract}
Ana Carolina Rodrigues Benvenho ${ }^{1}$, Rogério Luizari Guedes ${ }^{2}$, Peterson Triches Dornbusch ${ }^{3}$, Nilson Roberti Benites ${ }^{1}$, Angelo João Stopiglia ${ }^{1}$
\end{abstract}

\footnotetext{
${ }^{1}$ Faculdade de Medicina Veterinária e Zootecnia da Universidade de São Paulo, Brasil.

2 Universidade Tuiuti do Paraná, Curitiba, Paraná, Brasil. *Corresponding author: rogerioguedes@veterinario.med.br

${ }^{3}$ Universidade Federal do Paraná, Curitiba, Paraná, Brasil
}

\begin{abstract}
RESUMO: O colapso traqueal acomete principalmente cães de raças pequenas, de meia idade a idosos e seu diagnóstico é feito com base nos sinais clínicos e exames complementares. A traqueobroncoscopia permite avaliar o diâmetro da traqueia e dos segmentos brônquicos permitindo a coleta de amostras para citologia, histopatologia e culturas. O objetivo deste estudo foi verificar se há correlação entre infecção bacteriana e inflamação traqueal em cães com colapso traqueal. Foram selecionados 28 animais: doze apresentando colapso traqueal e 16 hígidos que passaram por procedimento de traqueobroncoscopia, avaliando-se a traqueia seguido da coleta de material para cultura bacteriana e citologia. Após a análise dos resultados foi observada correlação positiva entre a ocorrência de inflamação e colapso de traqueia. Não foi observada correlação entre infecção bacteriana e inflamação ou entre infecção e colapso. Com um teste de dissimilaridade verificou-se que a população bacteriana da orofaringe foi semelhante à da traqueia nos cães de um mesmo grupo. Conclui-se que cães com colapso traqueal tendem à presença de processo inflamatório, porém não estando relacionada a infecções bacterianas. A composição das bactérias na traqueia sugere aspiração do conteúdo da orofaringe.
\end{abstract}

Palavras-chave: estenose traqueal; cão; infecção bacteriana; inflamação; traqueobroncoscopia

ABSTRACT: The tracheal collapse affects mainly small breeds, middle-aged and older dogs and the diagnosis is made based on clinical signs and additional exams. The trachealbronchoscopy allows evaluating the trachea diameter and bronchial segments, especially when radiographic and fluoroscopy is not conclusive and still allows the collection of samples for cytology, histopathology and cultures. The objective of this study was evaluate if there is a correlation between bacterial tracheal infection and tracheal inflammation in dogs with tracheal collapse. The sample consisted of 28 dogs, including 12 with collapsing trachea and 16 healthy subjects in the control group. For data collection was used the trachealbronchoscopy, in which was visualized the trachea, collected samples for cytology and bacterial culture. After analyzing the results, we found positive correlation in inflammation and tracheal collapse. There was no correlation between bacterial infection and inflammation in the trachea. With dissimilarity test was observe that the bacterial population of the pharynx was similar to the trachea in dogs of the same group. In this study, therefore, concluded that dogs with collapsing trachea tend to have the inflamed trachea, but it does not have bacterial infection. 
The composition of the bacteria in the trachea may be due to aspiration of pharynx's contents.

Keywords: bacterial infection; dog; inflammation; tracheal stenosis; tracheobronchoscopy

\section{INTRODUÇÃO}

O colapso traqueal é uma obstrução parcial ou total da traqueia caracterizada pelo achatamento dorsoventral dos anéis cartilaginosos e pela frouxidão da membrana traqueal dorsal (Yeon et al., 2005). Esta alteração é atribuída a uma síndrome multifatorial ainda parcialmente incompreendida (Johnson, 2000; Maggiore, 2014). Apresenta-se como anormalidade primária na cartilagem, resultando em fraqueza dos anéis traqueais, devido à redução de glicoproteínas e glicosaminoglicanos (Bonagura e Twedt, 2009). Fatores secundários também são capazes de iniciar a progressão da doença, como tosse crônica, infecção bacteriana, doença cardíaca com compressão de traqueia e brônquios e traumatismo traqueal (Bojrab e Renegar, 1981).

Esta enfermidade acomete principalmente cães de raças pequenas de meia idade a idosos (White e Willians, 1994) que apresentam frequentemente sinais clínicos de tosse seca paroxística, principalmente em momentos de excitação (Ettinger, 2010). O colapso de traqueia pode ser diagnosticado com base em sinais clínicos e exames complementares como radiografias torácicas e cervicais, realizadas com projeções na inspiração e expiração, fundamentais para a confirmação do diagnóstico (Marolf et al., 2007). A fluoroscopia pode detectar alterações dinâmicas nas vias aéreas, mas a traqueobroncoscopia permite avaliar o diâmetro da traqueia e dos segmentos brônquicos, especialmente quando a radiografia e a fluoroscopia não forem conclusivas (Mcready et al.,
2007). Além disso, a broncoscopia permite coletar amostras para citologia, cultura, antibiograma e biópsias para exame histopatológico (Mccarthy, 2005).

Acredita-se que infecções bacterianas e inflamações supurativas constatadas na citologia piorem os sinais clínicos (Johnson e Fales, 2001), mesmo que o defeito esteja na estrutura da cartilagem. Uma vez que não foram encontrados trabalhos que definem a associação das duas etiologias supracitadas, este estudo tem o objetivo de avaliar a correlação entre o processo inflamatório no colapso de traqueia com a presença de infecção bacteriana.

\section{MATERIAL E MÉTODOS}

Foram selecionados 12 cães que apresentavam sintomatologia clínica sugestiva de afecção traqueal (Tabela 1). Foram considerados fatores de inclusão:anamnese, exame físico com reflexo de tosse positivo e ausculta traqueal, radiografias cervical e torácica compatíveis com sinais de colapso traqueal. Hemograma, creatinina, alanina-amino transferase e eletrocardiograma foram realizados para descartar alterações de outra natureza. Mediante os exames anteriores sugerissem 0 colapso traqueal, tal condição foi confirmada por procedimento de traqueobroncoscopia. Estes animais foram inseridos no grupo denominado Colapso de Traqueia (CT). Para a criação de um grupo Controle (C), foram selecionados 16 animais hígidos, sendo composto por cães encaminhados para realização de intervenções cirúrgicas eletivas de castração do Hospital Veterinário e cães da raça Beagle pertencentes ao 
Laboratório de Cirurgia Cárdio-torácica, ambos da Universidade de São Paulo.

Tabela 1 - Distribuição do Grupo Colapso de Traqueia (CT), segundo raça e idade.

\begin{tabular}{lll}
\hline Identificação & Raça & Idade \\
\hline CT1 & Pinscher & 2 anos \\
CT2 & Lulu da Pomerania & 4 anos \\
CT3 & Yorkshire & 2 anos \\
CT4 & Yorkshire & 2 anos \\
CT5 & Yorkshire & 7 anos \\
CT6 & Pug & 12 anos \\
CT7 & Poodle & 9 anos \\
CT8 & Yorkshire & 4 anos \\
CT9 & Maltes & 9 anos \\
CT10 & Yorkshire & 6 anos \\
CT11 & Pinscher & 3 anos \\
CT12 & Yorkshire & 1,5 ano \\
\hline
\end{tabular}

Os critérios de exclusão dos dois grupos foram: uso de antibioticoterapia por pelo menos um mês antes da broncoscopia; uso de terapia com antiinflamatórios esteroidais e nãoesteroidais por pelo menos quatro semanas e duas semanas, respectivamente, antes da broncoscopia; fêmeas gestantes; cães que apresentassem alterações pulmonares.

Os animais foram submetidos à anestesia geral, recebendo medicação pré-anestésica intramuscular com acepromazina $\quad\left(0,05 \quad \mathrm{mg} \cdot \mathrm{kg}^{-1}\right) \quad$ e meperidina (2 mg. $\left.\mathrm{kg}^{-1}\right)$. Para indução e manutenção da anestesia geral foi utilizado propofol (3-5 mg. $\mathrm{kg}^{-1}$, EV). Os cães foram submetidos a préoxigenação com máscara e oxigênio $100 \%$ durante 10 minutos, antes da indução anestésica. Para o exame endoscópico utilizou-se um broncoscópio com $5 \mathrm{~mm}$ de diâmetro e canal de trabalho de 2 mm (BF200, Olympus, EUA). Com 0 animal posicionado em decúbito esternal, foram coletadas amostras da mucosa faringeana com suabe estéril para cultura bacteriana. $O$ colapso foi identificado com a observação da redução no sentido dorsoventral do lúmen traqueal na porção cervical, entrada do tórax e porção torácica (Figura 1). O colapso dos brônquios principais também foi avaliado e, quando presente, considerado. Para a classificação do colapso de traqueia foi utilizada a graduação preconizada por Tangner e Hobson (1982).
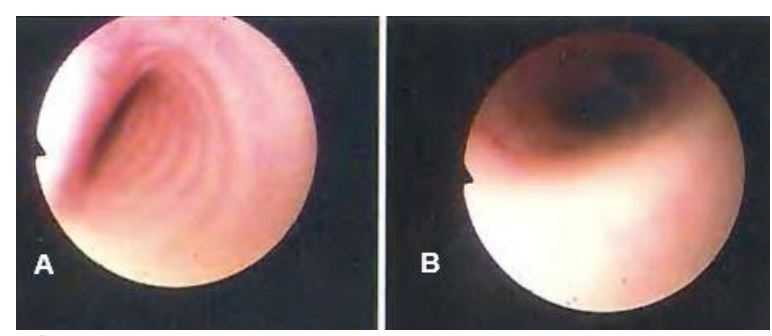

Figura 1 - Imagens do exame de traqueobroncoscopia em um dos animais do Grupo Colapso de Traqueia. Legenda - A: Traqueia cervical com colapso grau III e B: grau II em traqueia torácica.

Após a inspeção visual das vias aéreas foi introduzida uma escova de citologia estéril de $120 \mathrm{~mm}$ de comprimento, bainha de $1,8 \mathrm{~mm}$ de diâmetro e cerdas de $3 \mathrm{~mm}$ umedecidas com solução salina estéril, conforme sugerido por Mckiernan et al. (1984) sendo que as cerdas eram exteriorizadas da proteção na porção distal da traqueia. A utilização de um cateter recoberto por uma bainha que passa pelo canal de trabalho do endoscópio limitou a possibilidade de contaminação da orofaringe. As cerdas eram passadas delicadamente pela mucosa cerca de cinco vezes e o cateter era recolhido para o interior da bainha e removido do broncoscópio. 
Com a primeira amostra, o cateter era agitado em dois a $10 \mathrm{~mL}$ em meio de cultura celular estéril (caldo $\mathrm{BHI}$ Brain and Heart Infusion broth) ou colocado no meio de transporte (meio de Stuart). Visando a pesquisa de bactérias aeróbias e anaeróbias facultativas, os suabes foram inicialmente inoculados em caldo $\mathrm{BHI}$ com incubação a $37^{\circ} \mathrm{C}$ por 24 horas. As amostras também foram semeadas em ágar sangue de carneiro (5\%) e ágar MacConkey, com incubação em aerobiose a $37^{\circ} \mathrm{C}$, com leituras em 2496 horas. As amostras cultivadas em caldo $\mathrm{BHI}$ foram posteriormente semeadas em ágar sangue de carneiro (5\%) e ágar MacConkey, com incubação destas realizada de forma similar à descrita anteriormente para o cultivo inicial. Os microrganismos isolados foram identificados de acordo com Murray et al. (1999). Em casos de dúvida, foram utilizados os sistemas de identificação RapIDß Staph Plus System e NF Plus System (Remel, Estados Unidos).

Após esta etapa, foi coletada uma segunda amostra com nova escova estéril, que depois de retirada do broncoscópio era rolada gentilmente por uma lâmina seca de vidro de microscópio. As lâminas de citologia foram coradas pelo método May Grunwald-Giensa modificado (Rosenfeld) e avaliadas qualitativamente por um único investigador. Essas lâminas eram avaliadas conforme a celularidade (baixa, média e alta), presença de muco $(0,+,++,+++)$, presença de células epiteliais (presente ou ausente), displasia celular $(0,+,++$, +++ ), presença de células caliciformes $(0,+,++,+++)$, presença de células inflamatórias e tipo celular predominante (neutrófilo ou macrófago; $0,+,++,+++$ ) e presença de hemácias $(0$, raro,,+++ , +++ ). A presença de neutrófilos e a displasia encontrada na citologia foram os critérios utilizados para classificar o animal como portador de inflamação. Áreas com muitas escoriações ou com secreções visíveis foram evitadas durante a coleta de amostras.

Para testar a independência entre os fatores foi utilizado o teste exato de Fisher, considerando dependência significativa entre as amostras quando $p \leq 0,05$. Para avaliar a dissimilaridade entre as regiões amostradas (traqueia e orofaringe) e o grupo dos animais (CT e C) utilizou-se o índice de dissimilaridade baseado na distância de Bray-Curtis. $O$ número de animais infectados por cada tipo de bactéria foi padronizado pela presença ou ausência das bactérias. Não foram incluídos os resultados negativos, pois eles representam ausência de bactérias, e o objetivo desse teste foi verificar a similaridade da composição de espécies bacterianas entre as regiões amostradas de animais controle e doentes. Foi utilizado o pacote vegan do software $R \quad 2.12$ (Community Ecology Package. R packege 2.0-1).

\section{RESULTADOS E DISCUSSÃO}

\section{As alterações morfológicas} encontradas durante a traqueobroncoscopia foram facilmente evidenciadas e corroboram com as citadas pela literatura, como 0 achatamento dos anéis traqueais, membrana dorsal pendular e a alteração da coloração da mucosa traqueal (Mccarthy, 2005; Creevy, 2009). Também sendo possível avaliar a extensão e a severidade do colapso traqueal e a presença colapso nos brônquios principais (White e Williams, 1994; Buback et al., 1996; Becker et al., 2012).

Dos 28 cães avaliados, houve crescimento bacteriano em amostras de 93\% (Tabela 2). Em 12 animais as culturas foram obtidas somente da 
orofaringe ( $\mathrm{n}=6$, grupo $\mathrm{C} ; \mathrm{n}=6$, grupo CT); o crescimento exclusivo em traquéia ocorreu em apenas um animal do grupo $\mathrm{C}$ e o crescimento em ambas as regiões foi observado em 11 animais ( $n=8$, grupo $\mathrm{C} ; \mathrm{n}=3$, grupo $\mathrm{CT}$ ). Em dois cães não houve crescimento bacteriano de nenhum local, sendo um de cada grupo. Dentre as bactérias isoladas verificou-se que o Staphilococcus spp. foi a mais comumente isolada (11 culturas), porém se caracterizarmos essas bactérias observamos que houve crescimento de seis diferentes espécies. A segunda bactéria mais isolada foi a Escherichia coli (sete culturas) seguida pelo Streptococcus spp. (cinco culturas), o gênero Streptococcus também apresentou duas diferentes espécies. Outras bactérias isoladas foram Acinetobacter sp., Pseudomonas aeruginosa, Bacillus sp. e Klebsiella pneumoniae (3 culturas) e Flavobacterium IIj (uma cultura).

Em cães saudáveis e com colapso de traqueia a árvore traqueobronquica não é sempre estéril, pois conforme estudos de Mckiernan et al. (1984), Buback et al. (1996), Johnson e Fales (2001), Johnson e Pollard (2010) é comum isolar bactérias do trato respiratório inferior destes cães. No estudo realizado por Mckiernan et al. (1984) houve crescimento na traqueia em $36,4 \%$ dos cães, a população bacteriana da traqueia foi semelhante à da orofaringe em $80 \%$ dos animais, sendo o Streptococcus sp. a bactéria mais frequentemente isolada em ambas as regiões. Em outros estudos que avaliaram o crescimento das bactérias da traqueia em cães com colapso traqueal tem-se $94 \%$ de crescimento, sendo Staphylococcus sp., Pseudomonas sp., Corynebacterium sp., Pasteurella sp. e Escherichia coli as mais comumente isoladas (Buback et al., 1996). Johnson e Fales (2001) encontraram crescimento de bactérias em 29 dos 37 cães avaliados, sendo predominantes Pseudomonas sp. ( $\mathrm{n}=$ 17) e enterobacterias $(n=4)$. White e Williams (1994) descrevem 57\% de crescimento ( $\mathrm{n}=14)$, sendo Pseudomonas sp., coliformes e Staphylococcus sp. as mais presentes.

Tabela 2 - Distribuição do grupo controle e grupo colapso de acordo com o resultado a cultura bacteriana realizadas nas regiões orofaringe e traqueia.

\begin{tabular}{|c|c|c|}
\hline \multirow{2}{*}{ Identificação } & \multicolumn{2}{|c|}{ Regiảo } \\
\hline & Orofaringe & Traqueia \\
\hline C1 & Staphylococcus intermedius & Negativo \\
\hline C2 & Escherichia coli & Staphylococcus intermedius \\
\hline C3 & Escherichia coli & Flavobacterium IIj \\
\hline $\mathrm{C} 4$ & Escherichia coli & Negativo \\
\hline $\mathrm{C5}$ & Staphylococcus saprophyticus & Pseudomonas aeruginosa \\
\hline C6 & Staphylococcus saprophyticus & Klebsiella pneumoniae \\
\hline $\mathrm{C7}$ & Staphylococcus saprophyticus & Acinetobacter sp. \\
\hline $\mathrm{C} 8$ & Staphylococcus kloosii & Negativo \\
\hline C9 & Negativo & Acinetobacter sp. \\
\hline C10 & Staphylococcus capitis/ Bacillus & Staphylococcus kloosii \\
\hline C11 & Escherichia coli & Pseudomonas aeruginosa \\
\hline C12 & Escherichia coli & Negativo \\
\hline C13 & Staphylococcus capitis & Negativo \\
\hline C14 & Negativo & Negativo \\
\hline C15 & Streptococcus dysgalactiae & Streptococcus dysgalactiae \\
\hline C16 & Pseudomonas aeruginosa & Negativo \\
\hline CT1 & Acinetobacter $s p$. & Negativo \\
\hline СТ2 & Streptococcus equisimilis & Streptococcus equisimilis \\
\hline СТ3 & Bacillus sp. & Klebsiella pneumoniae \\
\hline CT4 & Escherichia coli & Escherichia coli \\
\hline СT5 & Klebsiella pneumoniae & Negativo \\
\hline ст6 & Negativo & Negativo \\
\hline $\mathrm{CT7}$ & Staphylococcus hominis & Negativo \\
\hline ст8 & Streptococcus dysgalactiae & Negativo \\
\hline СТ9 & Bacillus sp. & Negativo \\
\hline CT10 & Negativo & Negativo \\
\hline CT11 & Negativo & Negativo \\
\hline CT12 & Staphylococcus chromogenes & Negativo \\
\hline
\end{tabular}

do Grupo Colapso de Traqueia

No estudo de Johnson e Pollard (2010) houve crescimento em 16 dos 57 cães sem colapso e em seis dos 58 cães com colapso traqueal, os microorganismos que mais cresceram foram Bordetella sp, Mycoplasma sp e enterobacterias.

A porcentagem de dissimilaridade entre as populações bacterianas e as regiões de coleta de material para cultura foi realizada com o índice de dissimilaridade baseado na distância de 
Bray-Curtis (Tabela 3). Quanto mais próximo de $100 \%$, mais distintas são as populações. Neste trabalho pode-se inferir que a população bacteriana da orofaringe do grupo CT é semelhante à população da traqueia do mesmo grupo em $54,5 \%$. A população bacteriana da traqueia do grupo $\mathrm{C}$ se assemelha em aproximadamente $53 \%$ com a da respectiva orofaringe. Já a população bacteriana das orofaringes se assemelha em $38 \%$, e esta semelhança diminui para $20 \%$ quando avaliadas as populações presentes em traquéia. Estas informações corroboram com outros trabalhos (Mckiernan et al., 1984; Johnson e Fales, 2001) e mostram que a provável presença de bactérias na traqueia dos cães seja devido a aspiração do conteúdo da orofaringe. A disparidade entre os grupos na mesma região pode sugerir a possibilidade de haver uma mudança na microbiota dos cães com colapso, por consequência da sintomatologia clínica como tosse e dispneia.

Tabela 3 - Índice de dissimilaridade baseado na distância de Bray-Curtis entre as populações bacterianas e as regiões que foram realizadas coletas de amostras para cultura durante a traqueobroncoscopia em cães. Quanto mais próximo de 1,0 mais distintas são as populações.

\begin{tabular}{ccccc}
\hline \multirow{2}{*}{ Regiäo } & \multicolumn{3}{c}{ Grupo } & \multicolumn{2}{c}{ Controle } \\
\cline { 2 - 5 } & Orofaringe & Traqueia & Orofaringe & Traqueia \\
\hline Colapso & 0 & 0,454 & 0,625 & 0,600 \\
Orofaringe & & 0 & 0,818 & 0,800 \\
Colapso Traqueia & 0,454 & 0,818 & 0 & 0,466 \\
$\begin{array}{c}\text { Colapso } \\
\text { Orofaringe }\end{array}$ & 0,625 & 0,800 & 0,466 & 0 \\
Colapso Traqueia & 0,600 & & & \\
\hline
\end{tabular}

O método de coleta de amostras para citologia foi realizado devido a possibilidade de demora no encaminhamento das amostras para o laboratório, podendo comprometer a viabilidade das células. Outras formas de realizar a citologia por escovação são citadas como, a escovação da região escolhida e agitação em 2 a 10 $\mathrm{mL}$ de solução salina e as laminas são preparadas por uma citocentrifugação (Hawkins et al., 2006). Rebarb et al. (1980) relatam em seu estudo que as laminas preparadas por citocentrifugação foram preferidas, pois houve menos distorção das delicadas células epiteliais ciliadas. Os mesmos autores também afirmam que pode haver uma degeneração das células respiratórias que ficam armazenadas em solução salina por períodos maiores que 30 minutos, havendo mudanças como a perda de cílios e a degeneração leve do núcleo.

Tabela 4 - Resultado da citologia dos Grupos Controle (C) e Colapso de Traqueia (CT) de acordo com a celularidade $(\mathrm{Cel})^{1}$, presença de muco $(M)^{2}$, displasia $(D)^{3}$, células caliciformes (CelCal) ${ }^{4}$, células inflamatórias (Cellnf $)^{5}$, predominância célular $(P)^{6}$ e presença de hemácias $(H)^{7}$.

\begin{tabular}{|c|c|c|c|c|c|c|c|}
\hline Identificação & Cel & M & D & CelCal & Cellnf & $P$ & $\mathrm{H}$ \\
\hline $\mathrm{C1}$ & Baixa & + & $0^{*}$ & + & 0 & 0 & 0 \\
\hline $\mathrm{C} 2$ & Baixa & Raro & 0 & + & 0 & 0 & 0 \\
\hline $\begin{array}{l}\mathrm{C}_{3} \\
\mathrm{C} 4\end{array}$ & $\begin{array}{l}\text { Baixa } \\
\text { Alta }\end{array}$ & $\begin{array}{l}+ \\
++ \\
++\end{array}$ & $\begin{array}{l}0 \\
0\end{array}$ & $\begin{array}{l}+ \\
+\end{array}$ & $\begin{array}{l}0 \\
0\end{array}$ & $\begin{array}{l}0 \\
0\end{array}$ & $\begin{array}{l}0 \\
0\end{array}$ \\
\hline $\mathrm{C} 5$ & Alta & ++ & 0 & + & 0 & 0 & 0 \\
\hline $\mathrm{C} 6$ & Media & + & 0 & + & 0 & 0 & 0 \\
\hline $\mathrm{C} 7$ & Baixa & + & 0 & + & 0 & 0 & 0 \\
\hline C8 & Alta & ++ & 0 & + & 0 & 0 & 0 \\
\hline C9 & Media & ++ & 0 & + & 0 & 0 & 0 \\
\hline C10 & Media & ++ & 0 & + & 0 & 0 & 0 \\
\hline C11 & Baixa & + & 0 & + & 0 & 0 & 0 \\
\hline${ }_{C 12} 12$ & Media & $\stackrel{++}{++}$ & 0 & + & 0 & 0 & 0 \\
\hline $\begin{array}{l}C_{C 13} \\
\text { C14 }\end{array}$ & Media & $\begin{array}{l}+++ \\
++\end{array}$ & 0 & $\begin{array}{l}+ \\
+\end{array}$ & 0 & & 0 \\
\hline $\begin{array}{l}\text { C14 } \\
\text { C15 }\end{array}$ & $\begin{array}{l}\text { Medaa } \\
\text { Media }\end{array}$ & $\begin{array}{l}++ \\
++ \\
++\end{array}$ & 0 & + & 0 & 0 & 0 \\
\hline C16 & Baixa & + & 0 & + & 0 & 0 & 0 \\
\hline CT1 & Baixa & ++ & 0 & t & 0 & 0 & 0 \\
\hline CT2 & Media & ++ & 0 & Raro & 0 & 0 & 0 \\
\hline $\mathrm{CT}^{* * *}$ & - & - & - & & - & - & - \\
\hline ст4 & Alta & Raro & 0 & Raro & 0 & 0 & $\begin{array}{l}++ \\
+\end{array}$ \\
\hline CT5 & Media & ++ & 0 & ++ & 0 & & $\begin{array}{l}+ \\
+\end{array}$ \\
\hline ст6 & Alta & + & ++ & +++ & ++ & $\begin{array}{c}\text { Neutrofilo e } \\
\text { macrofago ativo }\end{array}$ & ++ \\
\hline CT7 & Media & + & ++ & +++ & ++ & Neutrofilo e & + \\
\hline ст8 & Media & ++ & 0 & Raro & 0 & $\begin{array}{l}\text { macrofago } \\
0\end{array}$ & + \\
\hline ст9 & Media & + & 0 & ++ & + & $\begin{array}{l}\text { Neutrofilo e } \\
\text { macrofago }\end{array}$ & + \\
\hline CT10 & Alta & +++ & + & + & t+ & Neutrofilo & + \\
\hline CT11 & Alta & +++ & + & + & t+ & Neutrofilo & ++ \\
\hline CT12 & Baixa & + & 0 & + & 0 & 0 & + \\
\hline 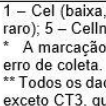 & & & & $3-$ & ++ & $\begin{array}{l}\text { CelCal }(+, \\
\text { de citologit }\end{array}$ & \\
\hline
\end{tabular}

As diferentes alterações citológicas encontradas na traqueia dos cães doentes e do grupo controle encontramse na Tabela 4. A citologia do grupo $C$ mostrou variação no resultado somente quanto à presença de muco. Oito amostras apresentaram ++ (50\%), seis animais apresentaram $+(37,5 \%)$, um animal $+++(6 \%)$ e um animal raro $(6 \%)$. No grupo CT a presença de muco foi verificada com ++ em 04 animais (33\%), + em 04 animais (33\%), +++ em 02 
animais (17\%) e raro em 01 animal (8\%).

As células epiteliais ciliadas foram predominantes na citologia tanto do grupo C quanto do grupo CT (Figura 2). No estudo de Johnson e Fales (2001) estas células também foram predominantes em 10 de 13 amostras e as células inflamatórias foram vistas em um pequeno número de amostras. Buback et al. (1996) encontraram na citologia de 56 cães a presença de inflamação séptica (23\%), hiperplasia epitelial (18\%), inflamação não-séptica $(18 \%)$, metaplasia $(5 \%)$ e nos $27 \%$ restantes os achados foram normais. Hawkins et al. (2006) também encontraram células epiteliais predominantemente na citologia por escovação de brônquios de cães saudáveis e outros com bronquite. Seguido das células epiteliais, as células caliciformes foram encontradas em menor quantidade. No grupo controle a quantidade de células caliciformes seguiram um padrão apresentando + em todas as amostras. Esperava-se encontrar aumento do número de células caliciformes e da produção de muco no grupo CT devido a injúria crônica, porem esta diferença não foi encontrada neste estudo. Em cães com bronquite crônica existe um aumento das células caliciformes (Wheeldon et al.,1974; Mckiernan et al., 1984), o que justifica a suspeita de encontrar um aumento das células caliciformes na traqueia. Porém em Hawkins et al. (2006) o número de células caliciformes não variou do grupo controle para o grupo de cães com bronquite. No grupo CT houve variações destas células, diferentemente de Johnson e Fales (2001), Buback et al. (1996), White e Williams (1994), que avaliaram a citologia em cães com colapso de traqueia e nenhum dos trabalhos cita a presença de células caliciformes ou muco.

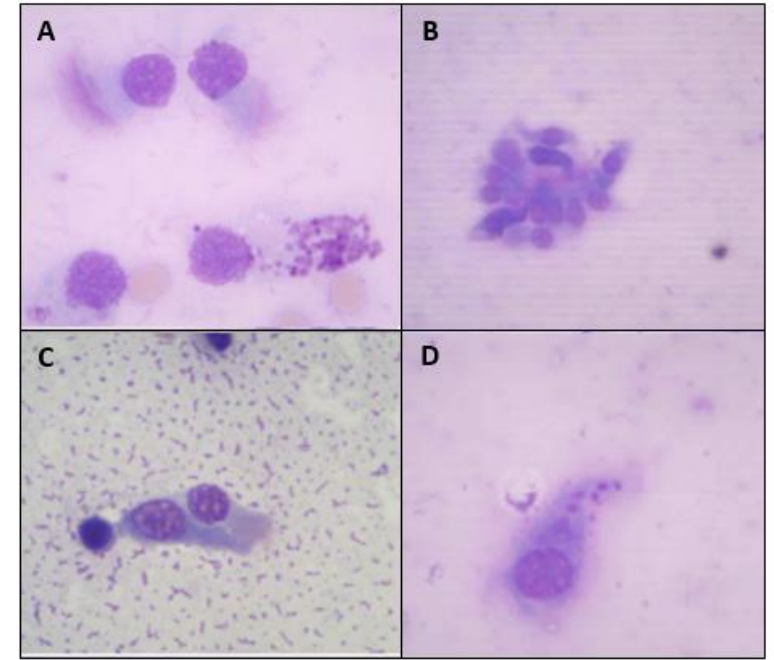

Figura 2 - Lâminas de citologia demonstrando os resultados dos diferentes achados citológicos. Legenda - A: Células epiteliais ciliadas e caliciformes em cão do Grupo Controle (100X; HE); B: células epiteliais ciliadas displásicas com o tamanho dos cílios e nucléolo bem reduzidos; C: células epiteliais displásicas em animal do Grupo Colapso de Traqueia (40X; $\mathrm{HE}$ ); D: célula caliciforme doente em animal do Grupo Colapso de Traqueia (100X; HE).

A presença de neutrófilos e displasia nas células epiteliais e caliciformes foi considerada indicativo de inflamação, pois nenhum cão do grupo controle apresentou essas alterações na citologia. O colapso de traqueia provoca tosse excessiva, iniciando um ciclo de injuria crônica. Durante a tosse as extremidades opostas da mucosa dos anéis traqueais entram em contato uma com a outra criando lesões na mucosa. A irritação crônica do epitélio resulta em alterações inflamatórias e comprometimento do sistema muco ciliar. Em quatro cães pode ser observada displasia, em dois deles esta displasia era apresentada como uma alteração no núcleo celular e uma diminuição do tamanho dos cílios. As células caliciformes também se encontravam displásicas, pois apresentavam poucos grânulos no citoplasma. Em dois dos outros cães as células caliciformes tinham aspecto mais jovem e as células epiteliais com citoplasmas de tamanho diferente mostrando uma maior proliferação. 
A correlação entre a inflamação e o colapso traqueal apresentou resultado significativo $(p<0,01)$, ou seja, animais com colapso tendem a apresentar inflamação. Não foi observada correlação entre a presença de colapso traqueal e presença de infecção nos cães do grupo CT e do grupo $C(p=$ 0,212 ), mesmo quando comparamos distintamente as infecções nas regiões da orofaringe com $\mathrm{p}=0,442 \mathrm{e}$ da traqueia com $p=0,273$. Encontramos relação significativa entre presença de inflamação com a não infecção da traqueia $(p=0,041)$. Todos os cães com inflamação da traqueia não apresentavam infecção nesta região. Como todos os cães que apresentaram a traqueia inflamada eram cães com colapso traqueal não houve correlação entre a presença de inflamação com a presença de bactérias na traqueia neste estudo. Num contexto geral, notou-se que nos cães que apresentaram inflamação não houve crescimento bacteriano na traqueia. Johnson e Pollard (2010) encontraram esta mesma observação na sua pesquisa. Johnson e Fales (2001) também não conseguiram estabelecer correlação entre o colapso e a infecção bacteriana na traqueia. Portanto, a utilização de antibióticos não se faz necessária nos casos de colapso traqueal. Entretanto, lembrando que caso o cão seja submetido a colocação de stents traqueais, o uso de antibiótico é necessário (Sura e Krahwinkel, 2008). Se houvesse presença de bactérias intracelulares na citologia poder-se-ia confirmar a presença de infecção (Creevy, 2009).

\section{CONCLUSÃO}

O presente estudo permite afirmar que a presença de processos inflamatórios é concomitante à presença de colapsos traqueais, porém não apresentam correlação com infecções bacterianas, sendo que os microrganismos identificados sugerem origem a partir da aspiração do conteúdo da orofaringe. Apesar da comprovação estatística dos dados, estudos mais abrangentes devem ser realizados para se obter a confirmação dos dados encontrados.

\section{COMITÊ DE ÉTICA E BIOSSEGURANÇA}

O presente estudo foi realizado após aprovação na Comissão de Ética no Uso de Animais da Faculdade de Medicina Veterinária e Zootecnia da Universidade de São Paulo sob 0 protocolo no 2061/2010.

\section{REFERENCES}

BECKER, W.M.; BEAL, M.; STANLEY, B.J. et al. Survival after surgery for tracheal collapse and the effect of intrathoracic collapse on survival. Veterinary Surgery, v.41, p.501-506, 2012.

BOJRAB, M.J.; RENEGAR, W.R. The trachea. In: Pathophysiology in small animal surgery. Philadelphia : Lea \& Febiger, 1981. Cap.38, p.359368.

BONAGURA, J.D; TWEDT, D.C. Kirk's current veterinary therapy XIV. St Louis : Elsevier Saunders, 2009. 1440 p.

BUBACK, J.L.; BOOTHE H.W.; HOBSON H.P. Surgical treatment of tracheal collapse in dogs: 90 cases (1983-1993). Journal of American Veterinary Medicine Association, v.208, n.3, p.380-384, 1996.

CREEVY, K.E. Airway evaluation and flexible endoscopic procedures in dogs and cats: laryngoscopy, tracheal wash, tracheobronchoscopy,

and 
bornchoalveolar lavage. Veterinary Clinics of North America - Small Animal Practice, v.39, n.5, p.872-879, 2009.

ETTINGER, S.J. Disease of the trachea and upper airways. In: Text book of veterinary internal medicine. 7.ed. St Louis : Elsevier, 2010. v.2, cap.228, p.1066-1088.

HAWKINS, E.C.; ROGALA, A.R.; LARGE, E.E. et al. Cellular composition of bronchial brushings obtained from healthy dogs and dogs with chronic cough and cytologic composition of bronchoalveolar lavage fluid obtained from dogs with chronic cough. American Journal of Veterinary Research, v.67, n.1, p.160167, 2006.

JOHNSON, L. Tracheal Collapse. Diagnosis and medical and surgical treatment. Veterinary Clinics of North America - Small Animal Practice, v.30, n.6, p.1253-1266, 2000.

JOHNSON, L.R.; FALES, W.H. Clinical and microbiologic findings in dogs with bronchoscopically diagnosed tracheal collapse: 37 cases (19901995). Journal of American Veterinary Medicine Association, v.219, n.9, p.1247-1250, 2001.

JOHNSON, L.R.; POLLARD, R.E. Tracheal collapse and bronchomalacia in dogs: 58 Cases (7/2001$1 / 2008)$. Journal of Veterinary Internal Medicine, v.24, p.298-305, 2010.

MAGGIORE, A.D. Tracheal and airway collapse in dogs. Veterinary Clinics of North America - Small Animal Practice, v.44, n.1, p.117-127, 2014.

MAROLF, A.; BLAIK M.; SPECHT, A. A Retrospective study of the relationship between tracheal collapse and bronchiectasis in dogs. Veterinary
Radiology \& Ultrasound, v.48, n.3, p.199-203, 2007.

MCCARTHY, T.C. Bronchoscopy. In:_. Veterinary endoscopy for the small animal practitioner. St Louis : Elsevier Saunders, 2005. p.201-227.

MCKIERNAN, B.C.; SMITH, A.R.; KISSIL M. Bacterial Isolates from the lower trachea of clinically healthy dogs. Journal of American Animal Hospital Association, v.20, p.139-142, 1984.

MCREADY, D.M.; JOHNSON, L.R.; POLLARD, R.E. Fluoroscopic and radiographic evaluation of tracheal collapse in dogs: 62 cases (20012006). Journal of American Vetereinary Medicine Association, v.230, n.12, p.1870-1876, 2007.

MURRAY, P. R.; BARON, E. J.; PFALLER, M.; TENOVER, F. C.; YOLKEN, R. H. In: Manual of clinical microbiology. 7. ed. Washington: American Society for Microbiology, 1999. p. $442-455$.

REBARB, A.H.; DENICOLA, D.B.; MUGGENBURG, B.A. Bronchopulmonary lavage cytology in the dog: normal findings. Veterinary Pathology, v.17, p.294-304, 1980.

SURA, P.A.; KRAHWINKEL, D.J. SelfExpanding nitinol stents for the treatment of tracheal collapse in dogs: 12 cases (2001-2004). Journal of the American Veterinary Medicine Association, v.232, n.2, p.228-236, 2008.

TANGNER, C.H.; HOBSON, H.P. A retrospective study of surgically managed cases of collapsed trachea. Veterinary Surgery, v.11, n.4, p.146-149, 1982. 
WHEELDON, E.B.; PIRIE, H.M.; FISHER, E.W. et al. Chronic bronchitis in a dog. Veterinary Record, n.94, p.466-471, 1974.

WHITE, R.A.S.; WILLIAMS, J.M. Tracheal collapse in the dog - is there really a role for surgery? A survey of 100 cases. Journal of Small Animal Practice, v.35, p.191-196, 1994.

YEON, S.C.; LEE, H.C.; CHANG, H.H. et al. Sound signature for identification of tracheal collapse and laryngeal paralysis in dogs. Journal of Veterinary Medical Science, n.67, v.1, p.91-95, 2005. 